\title{
Radiological impact of phosphogypsum discharged into the Venice lagoon: ${ }^{222} \mathrm{Rn}$
}

\author{
C. Cantaluppi, F. Ceccotto, A. Cianchi,
}

A. Fasson and S. Degetto

\begin{abstract}
CNR - Institute of Inorganic Chemistry and Surfaces - C.so Stati Uniti 4 35127 Padova, Italy
\end{abstract}

\begin{abstract}
For about 20 years, between the 60's and the 80's of the last century, in the Passo a Campalto area (Lagoon of Venice - Italy) about $400,000 \mathrm{~m}^{3}$ of phosphogypsum (PG) were deposited at the border of the lagoon and next to urban areas without any environmental control. These materials are a by-product formed during the wet processing of phosphate rocks by sulphuric acid and have a significant environmental impact due to their abundance and their chemical-physical and radiochemical characteristics. The PG contains both chemical elements, which are considered dangerous for the ecosystems and natural radionuclides whose concentrations are much higher if compared to those typical for the Earth's crust. These discarded materials caused for many years the dispersion of radionuclides in the environment due to the tidal erosion, the re-suspension of radioactive inhalable dusts, the uncontrolled radon exhalation and the bioaccumulation of some radionuclides in the lagoon environment. After a decision of the appointed authorities, the Venice Water Authority (Ministry of Infrastructure and Transport), planned a permanent safety control of the site resulting in the complete isolation of the entire volume of contaminated materials from the environmental system. The entire project was specific for the particular features of the site and it required the improvement of analytical, sampling and measurement techniques in order to verify the effectiveness of the safety action. The radon assessment, in particular the check of the effectiveness of the inhibition of radon exhalation, is part of a more complex study, covering many
\end{abstract}

This is an Open Access article distributed under the terms of the Creative Commons Attribution License 2.0, which permits unrestricted use, distribution, and reproduction in any medium, provided the original work is properly cited. 
other aspects of the management of a permanent disposal; they will be the object of further notes. The ultimate results of this study prove the efficacy of the intervention: radon concentrations in air and exhalation values from the restored area, measured during surveys, have been proved to be well in agreement with those of non contaminated soils.

\section{Introduction}

For about 20 years, between the 60's and the 80's of the last century, debris, hazardous waste and phosphogypsum were deposited without any environmental control and without considering the impact in the subsoil and lagoon waters [1]. The area concerned can be divided into two distinct areas: the West sector, about $150,000 \mathrm{~m}^{2}$, which contains various types of waste and the East sector, about $70,000 \mathrm{~m}^{2}$, which contains phosphogypsum, a byproduct of the Porto Marghera phosphate fertiliser industries (volume of about $400,000 \mathrm{~m}^{3}$ ) and which is characterized by deep and marked erosion towards the lagoon.

Phosphogypsum is an acidic by-product, formed during the wet processing of phosphate rocks by sulphuric acid. During this process, the radioactive equilibrium, existent among the various members appertaining to the decay series of ${ }^{232} \mathrm{Th}$ and ${ }^{238} \mathrm{U}$ contained in the phosphate rock, is disrupted and the radionuclides are partitioned into various phases according to their physical and chemical properties [2-4]. Uranium and Thorium distribute into the phosphoric acid liquid phase ( $\mathrm{U}$ and $\mathrm{Th}$ form soluble compounds with $\left(\mathrm{PO}_{4}\right)^{3-}$ ions), while most of the ${ }^{226} \mathrm{Ra}$ and ${ }^{210} \mathrm{~Pb}$ are enriched into the phosphogypsum solid phase because of the low solubility of their sulphates. The characteristics of the phosphogypsum vary according to the raw material used during the production process, whose concentration of radionuclides that are found later in the residues strongly depends on.

For this reason, from the radiological point of view, the main radioecological and radiation protection problems of PG come up from ${ }^{226} \mathrm{Ra}$ and daughters: ${ }^{222} \mathrm{Rn},{ }^{214} \mathrm{~Pb},{ }^{214} \mathrm{Bi},{ }^{210} \mathrm{~Pb}$ and ${ }^{210} \mathrm{Po}$.

Furthermore, a series of impurities remain "trapped" within the gypsum crystal aggregates [4] during the precipitation of $\mathrm{CaSO}_{4}$, which also include acid solutions containing $\left(\mathrm{PO}_{4}\right)^{3-}$ and $\mathrm{F}^{-}$ions. The area we focused on during our research has also a special environmental risk, because the phosphogypsum was deposited in a salt marsh area, within the bordering of the Venice lagoon, without any work of containment. 


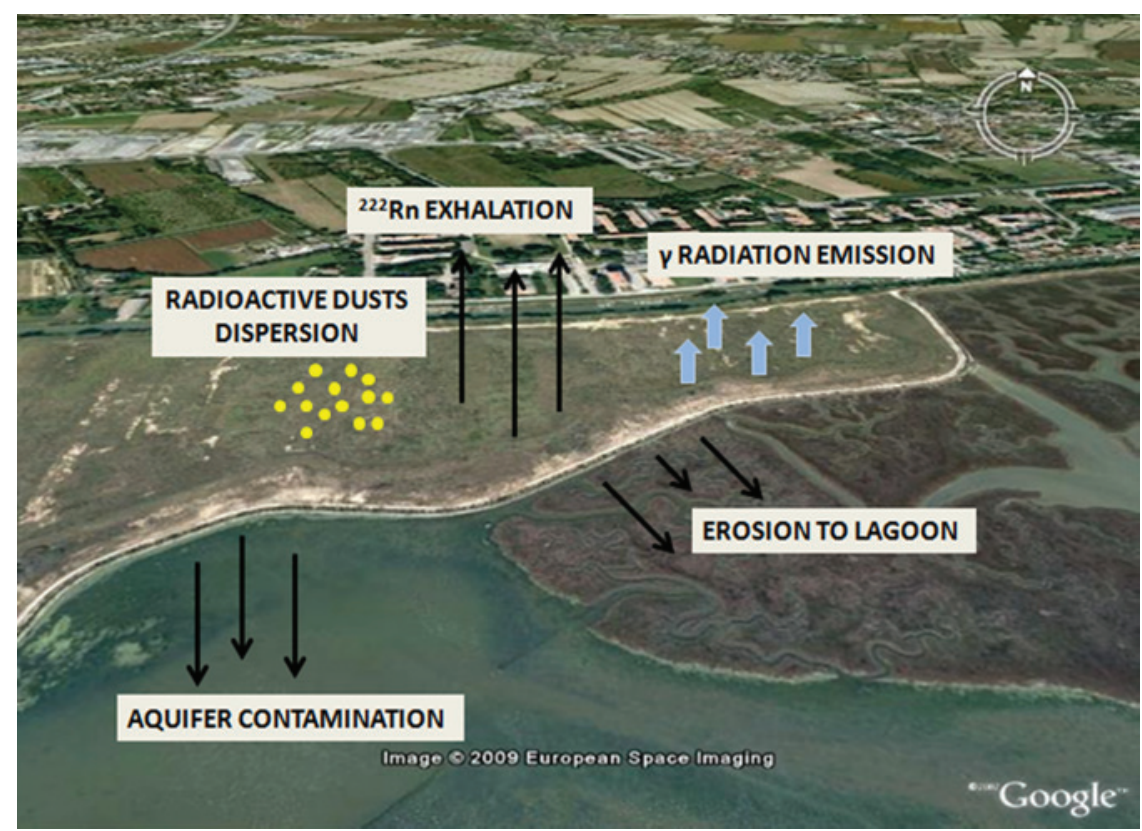

Fig. 1: Main environmental impacts of the phosphogypsum contaminated area (Passo a Campalto - Venice).

This involves many risks (fig. 1) such as:

- pollution of the surrounding areas due to erosion of the deposit itself, both as a result of rainfall and tidal waters, with dispersion of the eroded material into the lagoon;

- pollution of groundwater by leaching of PG due to run-off;

- emission of radioactive gas $\left({ }^{222} \mathrm{Rn}\right)$ from the surface of the deposit; since the piezometric level of the first layer communicates with the lagoon, it is quite likely that during the rising tide the different groundwater level inside the deposit pushes the radon, which originated from the entire mass of phosphogypsum, towards the surface;

- inhalation or ingestion of radioactive dust as a result of the phenomenon of wind re-suspension of surface dusts;

- bio-accumulation of radioactive substances in the biota in general and in mollusks in particular;

- direct gamma radiation exposure of people who have free access to the disposal area; 
- possible microbiological reduction of sulphates (by Sulphate Reducing Bacteria), with chemical and physical destabilization of the PG matrix.

Therefore, considering that the landfill is near to the residential areas and into a very fragile environment, the appointed authorities Venice Water Authority (Ministry of Infrastructures and Transports) through its concessionary Consorzio Venezia Nuova, carried out an urgent safety action [1].

The purpose of this action was the permanent containment of the entire volume of waste in order to:

- permit the complete isolation of the deposit and a complete environmental recovery of the area;

- make long-lasting the protection of the coast against the erosive action of waters;

- ensure the water seal of the work;

- set up a cover which prevents the penetration of rain water and slows down the radon exhalation, allowing its decay inside the deposit.

The safety action was performed through the creation of vertical barriers to prevent the flux of pollutants toward the lagoon and horizontal barriers

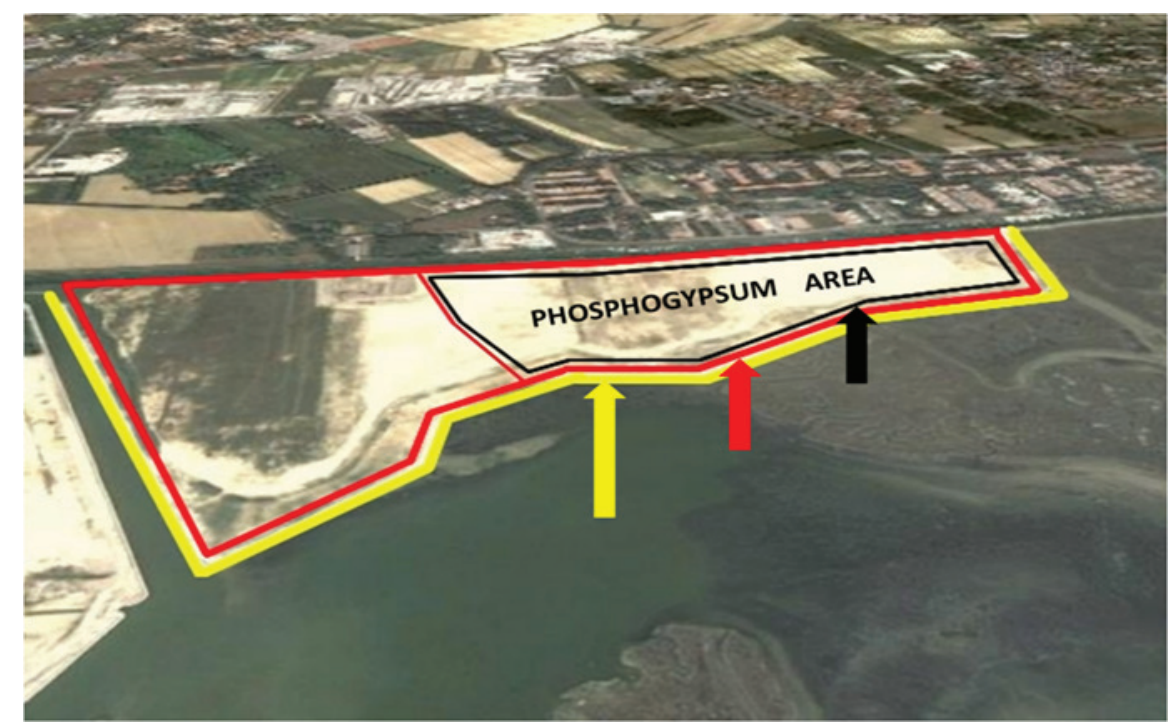

Fig. 2: Vertical barriers: structural barrier of metal sheet piling (yellow), plastic barrier (red), geochemical barrier (black). 
(covering layers) to slow down significantly the leak of radon gas, and prevent the deep percolation of rainwater (fig. 2).

The project of this permanent safety action was based on the impermeability of the existing deepest clay-silt consolidated layers (called "caranto" and laying below the mass of phosphogypsum), in order to isolate the materials deposited in the landfill from the underlying aquifers. During the survey there was the need to develop specific methods of investigation in order to assess the effectiveness to isolate the polluted mass over the years, and also to analyze and to monitor possible critical elements in the containment system (with a view to use this area as a public park).

In particular, this note concerns:

1. the measurement of the rate of radon exhalation coming out from the surface;

2. the continuous measurement of the activity concentration of radon in the air over the landfill.

\section{Materials and method}

\subsection{Measurement of ${ }^{222} \mathrm{Rn}$ exhalation from soil}

Radon exhalation can be affected by various factors such as:

- content of radium in the soil surrounding the measurement location;

- radon emanation coefficient of the piled up phosphogypsum;

- soil porosity;

- soil moisture;

- weather conditions (wet or dry).

Moreover, in this particular case, the changes of the piezometric level (due to tidal ranges) into the deposit may be very important.

After the safety actions, the flux of radon released from the soil covering the landfill depends on both the fraction originated within phosphogypsum (which can leak through barriers in measurable quantity) and the soil used for covering.

The purpose of this measurement is to calculate the present rate of radon exhalation $\left(\mathrm{Bq} \mathrm{m}{ }^{-2} \mathrm{~s}^{-1}\right)$ from the surface, in order to compare it to the one measured before the safety work and to detect possible radon leakages. 
Ten measurement locations were chosen, which were evenly distributed over the surface of the PG area.

In the first year the monitoring was carried out in four different periods (Campaign 1-4) in order to find out possible differences of radon exhalation under various weather conditions. The purpose was to identify the greater exhalation period.

The method used for measuring the radon exhalation from soil is based on the radon absorption on activated carbon and, later on, to measure daughters activity concentrations following the radioactive equilibrium.

The method, with appropriate adjustment, has been used for decades [57]. Our research laboratory has developed and tested the method used for this study; it consists in placing the radon collectors, containing about 200 grams of activated carbon, on the ground of the landfill surface, within a PVC tube (diameter of $10 \mathrm{~cm}$ ), inserted in the soil down to about $10 \mathrm{~cm}$.

Preliminary tests showed, in our operating condition, the complete absorption of the exhaled radon on the activated carbon, independently from weather conditions. We also take under control the possible input of the radon already present in the atmosphere.

For this study, the radon collectors were left on the ground for about 72 hours. This time length was helpful to fulfil some specific consideration such as:

1. the time integrated radon exhalation rate should cover many tidal ranges;

2. a relatively short measurement time compared to the conditions of dynamic equilibrium: in these conditions the build-up of radon is approximately a linear in function of the exposure time;

3. in this relatively short measuring time the exhaled radon is reasonably small, although fairly measurable; in these specific terms of use, the activated carbons introduced in the collectors allow the complete radon adsorption even during wet weather conditions.

After the field exposure of radon collectors, the activated carbon was transferred into a suitable Marinelli container. The measurement started after a few hours, in order to reach the radioactive equilibrium between ${ }^{222} \mathrm{Rn}$ and daughters ${ }^{214} \mathrm{~Pb},{ }^{214} \mathrm{Bi}$. These radionuclides were determined by High Resolution Gamma Spectrometry; the detector used for the radiometric analysis of radon daughters is n-type coaxial HPGe (high purity germanium detector) (relative efficiency $25.3 \%, \mathrm{FWHM}=0.833 \mathrm{keV}$ at $122 \mathrm{keV}, \mathrm{FWHM}=$ $1.75 \mathrm{keV}$ at $1332 \mathrm{keV}$ ). 


\subsection{Monitoring of radon concentration in air over the landfill}

The purpose of the measurement is the continuous radon monitoring in air in order to check the possible influence of both the weather conditions and the tidal excursions on the radon concentration in air over the landfill.

The instrument is a modular portable system for field monitoring of low levels of radon activity concentrations in the air. The system is composed of two parts: 1) a constant airflow sampling system (use either polytetrafluoroethylene (PTFE) or Teflon $\left.{ }^{\circledR}\right)$, which doesn't interact with radon adequately long in order to permit "toron" $\left({ }^{220} \mathrm{Rn}\right)$ decay. The input air sampled is silica dehydrated and filtered through a $0.45 \mu \mathrm{m}$ filter; 2) an alpha particle detector (alpha particles are originated from the decay of radon and daughters, after the entry of the gas radon (only) into the measuring flask). The flask is made up by a cylindrical shaped chamber (10 L volume), coated with a thin layer of $\mathrm{ZnS}(\mathrm{Ag})$ scintillator.

Every individual photon, originated from the impact of alpha particles against the scintillator, is picked up by the photomultiplier, processed by the electronic system and piled up by an home made specific software. An automatic adjustment system allows a constant sampling of air (up to $100 \mathrm{~L} \mathrm{~h}^{-1}$ ). A periodic calibration of the instrument, with a NIST source of ${ }^{226} \mathrm{Ra}$, certifies the accuracy of the measurements.

The measurements of radon concentration in air, over the landfill, as well as radon exhalation measurements, lasted for 3 days without a break. Thus we could detect any possible effect due to the contemporary tidal ranges.

In the first year of monitoring, we planned three measurement campaigns in different seasonal periods, characterised by different weather conditions. Afterwards, the measurements were carried out in the highest exhalation period, which was identified during the first year of monitoring.

\section{Results and discussion}

\subsection{Measurement of radon exhalation from the soil}

In fig. 3 all results of the radon exhalation rate from stations DEG 1-10 (for all campaigns) are compared; table I shows the main statistical parameters ${ }^{1}$.

In several measurement locations some data resulted strongly anomalous compared with the average of the exhalation rate. These anomalous values were considered outliers because they were over the +2 sigma gap and they

\footnotetext{
${ }^{1}$ It is worthwhile noting that the $4^{\text {th }}$ Campaign followed the previous one after only one month because of the very heavy rain falls observed during the $3^{\text {rd }}$ Campaign.
} 


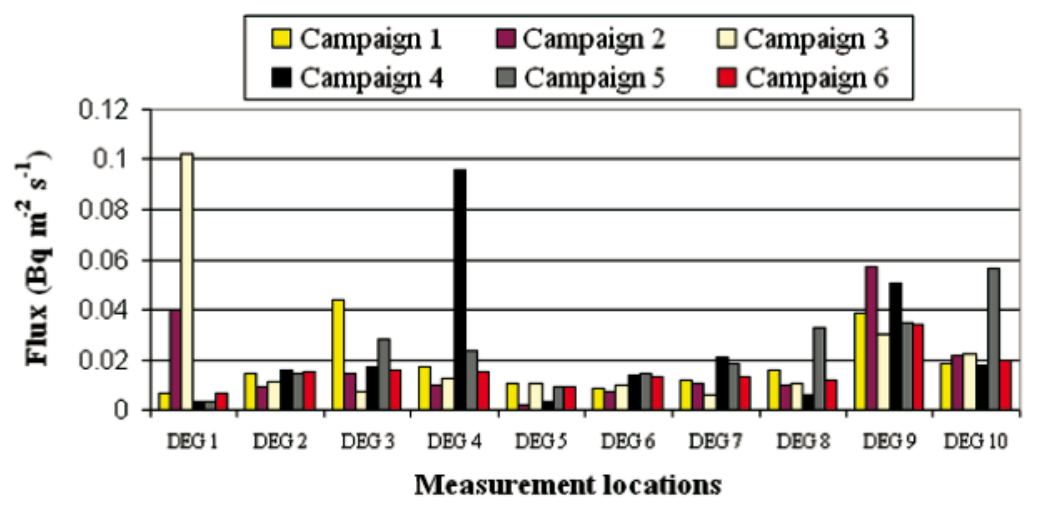

Fig. 3: Radon exhalation data of all campaigns, at the different measurement locations, (statistic error $<10 \%$ ).

were not present in all campaigns as a recurring theme. However, these "anomalous" data, even if it could alter the average of the overall campaigns, may be indicative of occasional and/or preferential ways of radon leakage, for this reason they cannot be ignored.

In fig. 4 all campaign data (averaged from all stations) are compared both with and without outliers.

The averages are not very different and fluctuate around the value $0.015 \mathrm{~Bq} \mathrm{~m}^{-2} \mathrm{~s}^{-1}$.

For what concerns the comparison of radon exhalation among the 10 measurement locations (fig. 5), the highest flux is found at DEG 9 station that could suggest a preferential way of radon leakage across the cover.

In table II the values of radon exhalation from the deposit (ante- and post-operam), together with the values found from a typical local soil with standard radium content are compared.

Table I: Statistics of the radon exhalation data.

\begin{tabular}{|l|c|c|c|c|c|c|}
\hline & $\begin{array}{c}\text { Campaign 1 } \\
\left(\mathrm{Bq} \mathrm{m}^{-2} \mathrm{~s}^{-1}\right)\end{array}$ & $\begin{array}{c}\text { Campaign 2 } \\
\left(\mathrm{Bq} \mathrm{m}^{-2} \mathrm{~s}^{-1}\right)\end{array}$ & $\begin{array}{c}\text { Campaign 3 } \\
\left(\mathrm{Bq} \mathrm{m}^{-2} \mathrm{~s}^{-1}\right)\end{array}$ & $\begin{array}{c}\text { Campaign 4 } \\
\left(\mathrm{Bq} \mathrm{m}^{-2} \mathrm{~s}^{-1}\right)\end{array}$ & $\begin{array}{c}\text { Campaign 5 } \\
\left(\mathrm{Bq} \mathrm{m}^{-2} \mathrm{~s}^{-1}\right)\end{array}$ & $\begin{array}{c}\text { Campaign 6 } \\
\left(\mathrm{Bq} \mathrm{m}^{-2} \mathrm{~s}^{-1}\right)\end{array}$ \\
\hline Mean & 0.0187 & 0.0183 & 0.0223 & 0.0244 & 0.0237 & 0.0155 \\
St. dev. $(\sigma)$ & 0.0128 & 0.0173 & 0.0290 & 0.0285 & 0.0155 & 0.0077 \\
Min & 0.0068 & 0.0019 & 0.0059 & 0.0032 & 0.0034 & 0.0063 \\
Max & 0.0444 & 0.0572 & 0.1021 & 0.0958 & 0.0568 & 0.0346 \\
Mean $-2 \sigma$ & -0.0068 & -0.0163 & -0.0358 & -0.0326 & -0.0073 & 0.0002 \\
Mean $+2 \sigma$ & 0.0442 & 0.0518 & 0.0804 & 0.0814 & 0.0546 & 0.0308 \\
\hline
\end{tabular}



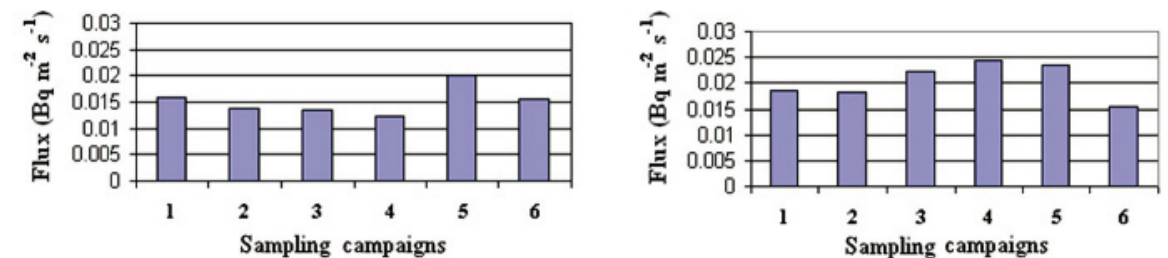

Fig. 4: Mean of the radon flux with (left) and without "anomalous" data (right) in the different campaigns.
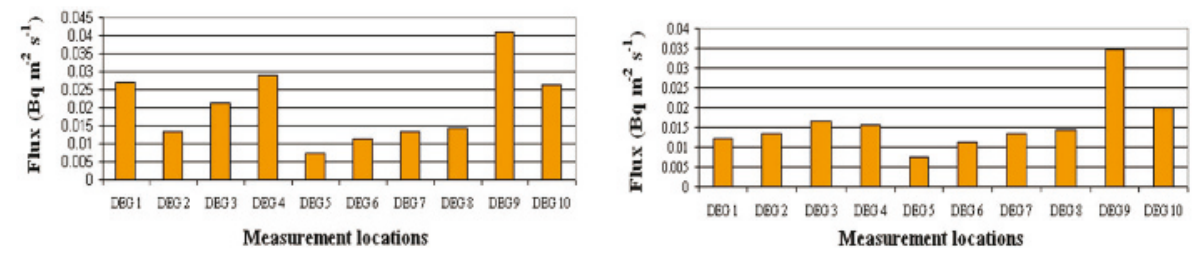

Fig. 5: Mean of radon flux on the six campaigns with (left) and without (right) "anomalous" data at the different measurement locations.

The values measured during the ante-operam preliminary tests were one order of magnitude higher than the post-operam values. Sometimes they were over the maximum limiting value required, according to EPA 1998, for industrial disposal areas i.e. $0.74 \mathrm{~Bq} \mathrm{~m}^{-2} \mathrm{~s}^{-1}$ of ${ }^{222} \mathrm{Rn}$. [8]. The average radon exhalation from local uncontaminated soil, without radium anomalies, $\left({ }^{226} \mathrm{Ra}=20-40 \mathrm{~Bq} \mathrm{~kg}^{-1}\right)$, [9], measured in different meteorological conditions, resulted in $0.060 \mathrm{~Bq} \mathrm{~m}^{-2} \mathrm{~s}^{-1}$, slightly higher than the averaged value found for the Passo a Campalto disposal area after the safety action [10].

Table II: Comparison of averaged values of ${ }^{222} \mathrm{Rn}$ flux in different cases.

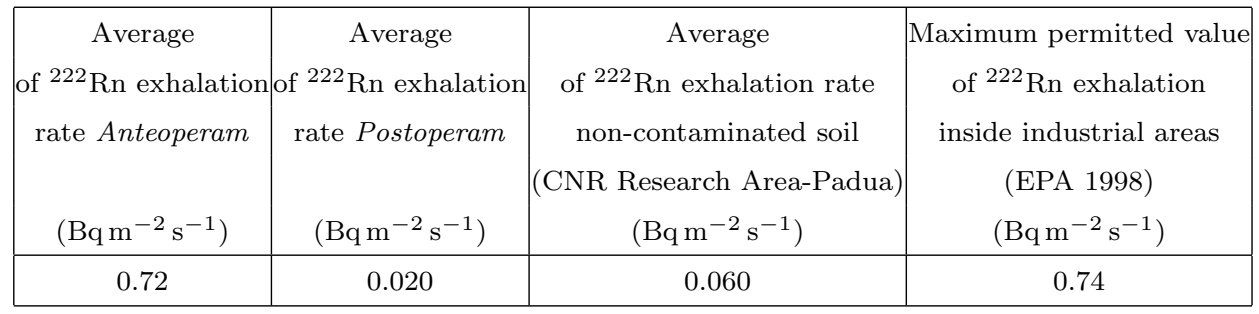




\subsection{Measurement of radon activity concentration in air}

The air sampling location was positioned in the center of the PG disposal area, recording in continuum the hourly averaged activity concentration of radon for about 72 hours.

Furthermore, comparison measurements were performed at the CNR research area of Padua (uncontaminated soil), in the days immediately before and after the measurements at the landfill.

These measurements lasted 3 years: $1^{\text {st }}$ Campaign $1^{\text {st }}$ year: spring; $2^{\text {nd }}$ Campaign $1^{\text {st }}$ year: summer; $3^{\text {rd }}$ Campaign $2^{\text {nd }}$ year: winter; $4^{\text {th }}$ Campaign $2^{\text {nd }}$ year: summer; $5^{\text {th }}$ Campaign $3^{\text {rd }}$ year: spring.

Usually the outdoor concentration of radon in air is influenced both by the radiochemical characteristics of soil and by the weather conditions. The data of radon exhalation over the landfill were compared to the values measured at the CNR research area at Padua where the radon exhalation is only originated from a quite "normal" radium content in the soil. Figure 6 shows the activity concentrations in the air over the disposal area that are quite similar to those found in the uncontaminated CNR-Research Area of Padua. In fact the average values of the radon activity concentration in air, at Campalto and Padua, were quite similar: $12.5 \mathrm{~Bq} \mathrm{~m}^{-3}$ at Padua and $12.6 \mathrm{~Bq} \mathrm{~m}^{-3}$ at Campalto.

Therefore, it is clear that the presence of $\mathrm{PG}$, after the remedy action, doesn't affect the activity concentration of radon measured over the landfill.

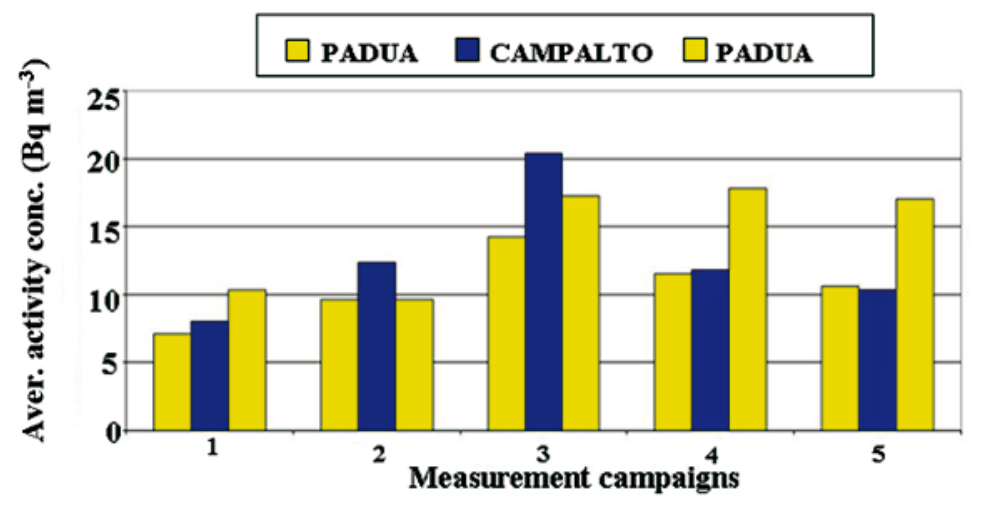

Fig. 6: Comparison between the radon averaged activity concentrations over the disposal area at Campalto and at Padua (uncontaminated soil). 


\section{Conclusions}

In this paper, the success of the remedy work performed at the PG disposal area as far as ${ }^{222} \mathrm{Rn}$ is concerned was monitored. In particular the study concerned: 1) the measurement of radon exhalation from the last layer (vegetated soil) covering the landfill and 2) the radon activity concentration in the air over the landfill.

The data of the radon flux showed a sharp decrease of radon exhalation from the landfill surface after the safety action: the average radon exhalation rate over the $\mathrm{PG}$ area, after the work, was $0.020 \mathrm{~Bq} \mathrm{~m}^{-2} \mathrm{~s}^{-1}$, much lower if compared with the exhalation measured before the containment work, $0.72 \mathrm{~Bq} \mathrm{~m}^{-2} \mathrm{~s}^{-1}$.

However, we observed permanently higher values of radon exhalation in a particular measurement location and this could highlight a preferential way of radon escape. In other cases a few anomalous high values were observed with a random distribution, possibly representing more than simple outlier values. Nevertheless, anomalous data were not discarded as they could represent particular situations of radon leakage.

The radon activity concentration profile $v s$. time in the air over the landfill has been compared with the piezometric water level inside the PG mass in order to recognize a possible correspondence with the "pumping" effect due to tidal ranges inside the PG mass. This measurement didn't show any supplementary effects due to the residual exhalation from the landfill surface and the value of the average activity concentration in air over the dumping area was very similar to the one of the reference area.

Therefore, after the safety action, the presence of PG appears to be not significant as regards both the radon exhalation rate and concentration in air.

\section{Acknowledgements}

This work was in part funded by the Venice Water Authority (Ministry of Infrastructure and Transport), through the Consorzio Venezia Nuova (Law $798 / 84$ ) as part of the complete reclamation of the area.

\section{References}

[1] Degetto S., Bernstein A. G. and Montobbio L., in Proceedings of VII International Waste Management and Landfill Symposium Sardinia '99, 
edited by T. H. Christensen, R. Cossu and R. Stegmann, Vol. 2 (CISA, Italy) 1999.

[2] Roessler C. E., Smith Z. A, Bolch W. E. and Prince R. J., Health Phys., 37 (1979a) 269.

[3] Lardinoye M. H., Weterings K. and Van Der Berg W. B., Health Phys., 42 (1982) 503.

[4] Rutherford P. M., Dudas M. J. and Semek R. A., The Science of the Total Environment 149 (1994) 1.

[5] Cohen B. L. and Cohen E. S., Health Phys., 45 (1983) 501.

[6] George A. C., Health Phys., 46 (1984) 867.

[7] Prichard H. M. and Marien K., Health Phys., 48 (1985) 797.

[8] Degetto S., Cianchi A., Cantaluppi C., Montobbio L. and Are D., in Book of Abstracts of the 5th International Conference on Methods and Applications of Radioanalytical Chemistry-Marc V (American Nuclear Society International, Kailua Kona USA) 2000, p. 80.

[9] Marani C., Environmental Chemistry Thesis, Determinazione del flusso atmosferico di ${ }^{210} \mathrm{~Pb}$ mediante analisi dei depositi al suolo, Academic Year 1999-2000, University of Bologna.

[10] Donati S., Environmental Chemistry Thesis, Distribuzione del contenuto di elementi chimici radioattivi e stabili in Pinus Pinaster e prospettive di utilizzo in dendroanalisi, Academic Year 2001-2002, University of Bologna. 